\title{
SALIVARY ALPHA AMYLASE LEVELS DURING PRIMARY TOOTH EXTRACTION IN CHILDREN AGED 6-11 YEARS
}

\author{
FARAGHEA YUMASDHIKA ${ }^{1}$, MARGARETHA SUHARSINI ${ }^{2 *}$, IKE SITI INDIARTI ${ }^{2}$, HASTIN DIAN ANGGRAENI ${ }^{1}$ \\ ${ }^{1}$ Department of , Pediatric Dentistry Residency Program, Faculty of Dentistry, Universitas Indonesia, Indonesia. ${ }^{2}$ Department of \\ Pediatric Dentistry, Faculty of Dentistry, Universitas Indonesia, Indonesia. Email: margarethasuharsini@gmail.com
}

Received: 16 September 2017, Revised and Accepted: 3 October 2017

\section{ABSTRACT}

Objective: Patients generally experience some level of anxiety during dental treatments. Salivary alpha amylase (SAA) can be used as a biomarker for anxiety.

This study aimed to compare SAA levels between children who had never and had undergone tooth extraction procedures with a local anesthetic injection.

Methods: Thirty-seven participants aged 6-11 years who were to undergo the extraction of primary teeth at the Dental and Oral Educational Hospital, Faculty of Dentistry Universitas Indonesia, were enrolled. The subjects were divided into two groups: One group consists of 20 children who had never undergone a tooth extraction, and the other group consists of 17 children who had undergone tooth extraction. From all children, one saliva sample was collected using a portable saliva strip 10 min before (t0), shortly after (t1), and 10 min after (t2) local anesthetic injection, and the SAA activity was determined using a portable Nipro Cocoro Meter device. The SAA levels of both groups were analyzed using the Mann-Whitney U test.

Results: There were significant differences in SAA levels at t0 ( $\mathrm{p}=0.001), \mathrm{t} 1(\mathrm{p}=0.018)$, and $\mathrm{t} 2$ ( $\mathrm{p}=0.021)$ in both groups. Anxiety is a combination of behavioral and physiological reactions. SAA release is regulated by autonomic innervation, and the SAA level increases owing to acute stress.

Conclusion: Dentists should note patients' negative dental experiences to provide more effective and less traumatic treatment.

Keywords: Salivary alpha amylase levels, Anxiety, Tooth extraction, Children aged 6-11 years.

(C) 2017 The Authors. Published by Innovare Academic Sciences Pvt Ltd. This is an open access article under the CC BY license (http://creativecommons. org/licenses/by/4. 0/) DOI: http://dx.doi.org/10.22159/ijap.2017.v9s2.33

\section{INTRODUCTION}

The extraction of primary teeth with a local anesthetic injection may cause pain and increase anxiety in children. Anxiety and fear of pain associated with dental treatment have remained a constant over time despite advances in dental equipment, procedures, and preventive measures. Dental anxiety is a confounding problem that dentists must cope with. Psychological stress can produce effects in various physiological systems that are similar to those produced by physical changes due to the activation of two stress response systems. These systems are the sympathetic-adrenal-medullary axis and hypothalamus-pituitary-adrenal axis [1]. Oosterink identified dental treatments and conditions that provoked anxiety. Tooth extraction is one such dental treatment [2]. Salivary alpha amylase (SAA) is one of the major protein components of saliva. It is synthesized and secreted by acinar cells. Previous studies have shown a correlation between psychological stress and SAA activity. Stress incudes significant increases in SAA [3].

Many studies have used portable devices to measure SAA levels. Such devices use a precursor colorimetric assay platform in which the color intensity of the enzymatic reaction product is measured photo metrically to determine the SAA concentration [4]. The total time needed to analyze saliva is $1 \mathrm{~min}$, including $30 \mathrm{~s}$ to collect saliva, $10 \mathrm{~s}$ to transcript saliva and $20 \mathrm{~s}$ for the reaction time [5].

The present study aims to compare the SAA level between children who had never and had undergone tooth extraction during a tooth extraction procedure with a local anesthetic injection.

\section{METHODS}

Thirty-seven children aged 6-11 years who were to undergo the extraction of a primary tooth at the Dental and Oral Educational Hospital, Faculty of Dentistry, Universitas Indonesia, were enrolled to participate in this study. Written informed consent was obtained from the children's parents or caregivers before taking samples. The protocol and patients' informed consent forms were approved by the Ethics Committee of Faculty of Dentistry, Universitas Indonesia.

SAA was determined $10 \mathrm{~min}$ before (t0), shortly after (t1), and $10 \mathrm{~min}$ after (t2) the injection of local anesthetic from both groups. A saliva strip was inserted sublingually to collect saliva. The SAA level was then determined. We used a handheld monitor (Nipro Co., Japan) and reagent paper to measure the enzymatic SAA activity. This measurement method can be performed easily and quickly, and it has been evaluated and used previously [4].

After examination and diagnosis determination, topical anesthetic with ultradent $20 \%$ benzocaine gel was applied at mucobuccal fold area closest to the extracted tooth for $1 \mathrm{~min}$. Then, local anesthetic with Articaine $\mathrm{HCl}$ $4 \%$ with epinephrine 1:100,000 (Septocaine-Septodont) was injected through a Morita 30G dental needle using a Paroject intra ligamental syringe. The SAA level between children who had never and had undergone tooth extraction was analyzed using the Mann-Whitney U test.

\section{RESULTS}

The mean SAA level of 20 children who had never undergone tooth extraction was higher than that of 17 children who had undergone extraction before, as shown in Table 1. 
Table 1: Mean and standard deviation of SAA levels $10 \mathrm{~min}$ before, shortly after, and $10 \mathrm{~min}$ after injection of local anesthetic

\begin{tabular}{llll}
\hline Group & Mean \pm SD & & \\
\cline { 2 - 4 } & $\mathbf{1 0} \mathbf{m i n}$ before $(\mathbf{t} \mathbf{0})(\mathbf{u} / \mathbf{m l})$ & Shortly after $(\mathbf{t} \mathbf{)})(\mathbf{u} / \mathbf{m l})$ & $\mathbf{1 0 ~} \mathbf{m i n}$ after $(\mathbf{t} 2)(\mathbf{u} / \mathbf{m l})$ \\
\hline Never undergone tooth extraction & $49.65 \pm 28.987$ & $56.40 \pm 37.397$ & $44.80 \pm 24.962$ \\
Undergone tooth extraction & $24.12 \pm 13.793$ & $35.00 \pm 29.148$ & $28.65 \pm 19.141$ \\
\hline
\end{tabular}

SD: Standard deviation, SAA: Salivary alpha amylase

There is a statistically significant difference in SAA level between the two groups at 10 min before (t0), shortly after ( $\mathrm{t} 1$ ), and 10 min after (t2) the infiltration injection of the local anesthetic (Table 2).

\section{DISCUSSION}

This study aimed to investigate the SAA level during dental treatment. The results show significant differences in SAA levels 10 min before dental treatment, shortly after dental treatment, and 10 min after dental treatment between children who had never undergone tooth extraction and who had undergone tooth extraction ( $\mathrm{t} 0[\mathrm{p}=0.001]$, $\mathrm{t} 1[\mathrm{p}=0.018]$, and $\mathrm{t} 2[=0.021])$.

A previous study showed that psychological stress and anxiety can significantly increase SAA levels [6]. A more recent study showed a correlation between the SAA level and the state-trait anxiety inventory score after watching a video about corneal transplant surgery [7]. Gyergyay stated that the SAA level can be used as a biomarker of fear and anxiety [7]. In the present study, at all three measurement times, SAA levels in children who had never undergone tooth extraction were significantly higher than those in children who had undergone tooth extraction. The results were similar to those reported by de Menezes Abreu et al. who found decreased levels of anxiety with an increase in the number of dental visits [8].

Dental anxiety has been a matter of concern for many years. It is generally accepted that dental anxiety predominantly starts during childhood. Venham studied the response of children during sequential dental visits, and found that negative behaviors decreased as the children became familiarized with the dental procedures [9].

This outcome differs from that of a previous study that found an increase in dental anxiety prevalence [10]. The difference between these two studies may lie in the difference in the methods used. The previous study used a prospective cohort study, whereas the present study used a cross-sectional study.

Hmud noted a few reasons for dental anxiety. Literatures have reported various primary factors including fear of pain, past traumatic dental experiences, and maternal anxiety. Studies have indicated that the memory of dental pain is reconstructed over time [10]. Nevertheless, not everyone develops dental anxiety after a painful dental treatment.

\section{CONCLUSION}

The present study suggests that there were differences in SAA levels between children who had never and had undergone tooth extraction and that these might lead to differences in anxiety levels. Dentist should note patients' negative dental experiences to provide more effective and less traumatic treatment. However, a cohort study is required to
Table 2: Statistically significant differences in Mann-Whitney

$\mathrm{U}$ test between children who had never undergone tooth extraction and children who had undergone tooth extraction

\begin{tabular}{lll}
\hline 10 min before $(\mathrm{t} 0)$ & Shortly after $(\mathrm{t} 1)$ & 10 min after $(\mathrm{t} 2)$ \\
$0.001^{*}$ & $0.018^{*}$ & $0.021^{*}$ \\
\hline${ }^{*} \mathrm{p}<0.05$ & &
\end{tabular}

confirm whether the number of dental treatments can influence the SAA level and, in turn, the anxiety level.

\section{ACKNOWLEDGMENT}

The authors thank to PITTA Grant from Directorate of Research and Community Service Universitas Indonesia for financially supporting this research. The publication of this manuscript is supported by Universitas Indonesia.

\section{REFERENCES}

1. Koh D, Ng V, Naing L. Alpha amylase as a salivary biomarker of acute stress of venepuncture from periodic medical examinations. Front Public Health 2014;2:121

2. Oosterink FM, de Jongh A, Aartman IH. What are people afraid of during dental treatment? Anxiety-provoking capacity of 67 stimuli characteristic of the dental setting. Eur J Oral Sci 2008;116:44-51.

3. Strahler J, Mueller A, Rosenloecher F, Kirschbaum C, Rohleder N. Salivary alpha-amylase stress reactivity across different age groups. Psychophysiology 2010;47:587-95.

4. Yamaguchi M, Kanemori T, Kanemaru M, Takai N, Mizuno Y, Yoshida $\mathrm{H}$, et al. Performance evaluation of salivary amylase activity monitor. Biosens Bioelectron 2004;20:491-7.

5. Higashi T, Mizuno Y, Yamaguchi M. Development of Sympathetic Nervous System Activity Monitor Using Salivary Amylase Activity. Technical Papers and Articles; 2005.

6. Bosch JA, Brand HS, Ligtenberg TJ, Bermond B, Hoogstraten J, Nieuw Amerongen AV. Psychological stress as a determinant of protein levels and salivary-induced aggregation of no impact of saliva flow rate on amylase stress response 651 streptococcus gordonii in human whole saliva. Psychosom Med 1996;58:374-82.

7. Engert V, Vogel S, Efanov SI, Duchesne A, Corbo V, Ali N, et al. Investigation into the cross-correlation of salivary cortisol and alphaamylase responses to psychological stress. Psychoneuroendocrinology 2011;36:1294-302.

8. de Menezes Abreu DM, Leal SC, Mulder J, Frencken JE. Patterns of dental anxiety in children after sequential dental visits. Eur Arch Paediatr Dent 2011;12:298-302.

9. Goettems ML, Ardenghi TM, Romano AR, Demarco FF, Torriani DD. Influence of maternal dental anxiety on the child's dental caries experience. Caries Res 2012;46:3-8.

10. Hmud R, Walsh L. Dental anxiety: Causes, complications and management approaches. J Minim Interv Dent 2009;2:67-78. 